InterAção | 99

\title{
RELAÇÕES ENTRE BRASIL E ÍNDIA: RESGATE HISTÓRICO E POTENCIALIDADES ESTRATÉGICAS ATUAIS
}

\author{
Edson José Neves Júnior ${ }^{1}$
}

\section{Resumo}

As relações entre Brasil e Índia têm demonstrado crescimento significativo nos últimos anos, de acordo com a tendência da cooperação sentido Sul-Sul. Contribuiu para esse aprofundamento alguns fatores relacionados à parceria histórica e contemporânea em fóruns internacionais de negociação multilateral, como a atuação articulada no G-20, a formação do Fórum de Diálogo Índia, Brasil e África do Sul - IBAS, em 2003; e a crescente participação coordenada no grupo BRIC. Em função desta recente convergência, resta averiguar quais os limites colocados para essa aliança e qual o grau de interdependência derivado de sua aproximação. Este artigo parte da premissa que o crescimento da colaboração entre estes dois países ocorre pela mudança na conjuntura mundial, onde um cenário multipolar se consolida em oposição às tentativas de recuperação hegemônica operadas pelos EUA, desde 2001, e também pelo aumento evidente das divergências econômicas e políticas entre países desenvolvidos e em desenvolvimento.

Palavras-Chave: Relações Internacionais entre Brasil e Índia; Comércio

1 Doutorando em Estudos Estratégicos Internacionais, Mestre em Relações Internacionais e Graduado em História, todos pela Universidade Federal do Rio Grande do Sul (UFRGS). Professor de História do Ensino Médio municipal. E-mail: edsonufrgs@yahoo.com 
100 | InterAção

Brasil-Índia; Cooperação Sul-Sul; Fórum IBAS.

\section{Abstract}

The Brazil India relations have shown significant growth in recent years, according with the trend of South-South cooperation. Contributed to increase depth of this partnership several factors related to historical and contemporary alliances in international multilateral negotiation, as articulated action on the G-20, the formation of the Dialogue Forum India, Brazil and South Africa - IBSA in 2003, and increasing participation coordinated in BRIC group. In light of this recent convergence, it remains to ascertain what are the limits placed for this alliance and what degree of interdependence derived from his approach. This paper assumes that the growth of cooperation between the two countries is the change in the world situation, where a multipolar scenario consolidates itself in opposition to attempts to rescues hegemonic role for U.S.A., operated since 2001, and also by enlargement of disagreements and economic policies between developed and developing countries.

Keywords: International Relations between Brazil and India, India-Brazil trade, South-South Cooperation; IBSA Forum.

\section{INTRODUÇÃO}

No cenário internacional, conformado nas últimas duas décadas, que teve como acontecimentos determinantes o fim da Guerra Fria 
InterAção | 101

e os atentados terroristas de 2001, têm adquirido crescente importância os países que demonstram grande importância regional associada a fatores tradicionais de prestígio político como uma significativa população, vasta extensão territorial e poderio militar. Brasil e Índia, em uma perspectiva geral, se apresentam como Estados deste tipo.

Chama atenção a progressiva aproximação operada entre estes dois atores na cena mundial, fazendo crer na possibilidade de atuação conjunta, o que se reflete, por exemplo, na criação do Fórum Índia, Brasil e África do Sul (IBAS), um organismo político intercontinental criado em 2003, e na constituição do Grupo BRIC (Brasil, Rússia, Índia e China), a princípio apenas uma sigla, cunhada em 2001, mas que se tornou um grupo internacional, de fato, em maio de $2008^{2}$. Contudo, é importante compreender as origens da aproximação entre Brasil e Índia e avaliar a sua real consistência.

Assim, este artigo tem por metas oferecer uma análise da história da cooperação bilateral entre Brasil e Índia, nas parcerias em espaços multilaterais de negociação internacional e na constituição e finalidades do fórum trilateral do IBAS e no grupo do BRIC. Para abordar as relações bilaterais utilizamos, basicamente, da diplomacia entre os dois países e de suas relações comerciais. Para os espaços multilaterais, avalio

\footnotetext{
20 termo BRIC foi criado pelo economista Jim 0’Neil, em 2001, por meio de um estudo intitulado Building Better Global Economic BRICs. Desde então, algumas reuniões entre representantes dos países foram efetivadas, mas foi somente em maio de 2008, a partir de uma Reunião dos Chanceleres dos quatro países em Ecaterimburgo, é que o grupo se tornou formal, com seus integrantes declarando compartilhar de interesses comuns nas áreas da política e da economia e se comprometerem a realizar encontro anual para discutir temas pertinentes ao cenário internacional contemporâneo. (MRE, Informações Gerais sobre o Grupo BRIC).
} 
102 | InterAção

qual a importância das ações coordenadas em fóruns como a OMC (Organização Mundial do Comércio), Conselho de Segurança das Nações Unidas e outros, e na criação do Fórum do IBAS e do grupo BRIC.

O resultado evidente na análise das relações entre Brasil e Índia é que, em termos históricos, a cooperação bilateral, nos quesitos diplomacia e comércio exterior, foi muito reduzida e restrita à breves conjunturas de aproximação; ao contrário de atuações articuladas em espaços internacionais multilaterais, como aqueles dedicados aos temas da economia e comércio, como a UNCTAD (United Nations Conference on Trade and Development), FMI (Fundo Monetário Internacional), Banco Mundial e OMC; e de segurança, como o Conselho de Segurança da ONU.

\section{Breve História das Relações Diplomáticas entre Brasil e Índia.}

No campo diplomático, as relações entre Brasil e Índia iniciaram com a independência indiana, tendo do lado indiano personagens como Mahatma Gandhi e Jawaharlal Nehru e da parte brasileira, o presidente Eurico Gaspar Dutra. Já em 1948, foi instalada a primeira embaixada indiana no Brasil, após visita e "apresentação de credenciais" do embaixador indiano Minoo Masani (VIEIRA, 2007, p. 52). Depois destes episódios de "inauguração" das relações entre os dois países, houve uma série de acontecimentos que, contudo, marcaram negativamente tais relações. Todos eles se referem à posição brasileira em relação às colônias portuguesas na Índia.

Ocorrida a independência indiana, restaram, contudo, alguns problemas territoriais não solucionados. Alguns deles reportavam às pequenas colônias portuguesas remanescentes de Goa, Damão e Diu, 
InterAção | 103

ainda pertencentes à Portugal, visto que a independência conquistada junto à Inglaterra não abrangia estes entrepostos incrustados na recém-criada União Indiana.

A Índia, por considerar aqueles territórios seus, solicitou a Portugal que cedesse formalmente a sua administração ao governo indiano. Portugal, por seu turno, receoso de que a libertação das colônias na Índia pudesse estimular a luta em suas outras possessões na África, rejeitou qualquer acordo com os indianos. $\mathrm{O}$ impasse só teve seu desfecho com a ocupação militar dessas áreas pelo exército indiano em 1961, passada mais de uma década de embates diplomáticos e duras negociações na Organização das Nações Unidas. Interessa trazer à análise esse fato pelo envolvimento que teve o Brasil ao longo do episódio e pela sua relevância para as relações entre Brasil e Índia nos anos posteriores.

De acordo com o Tratado de Amizade e Consulta entre o Brasil e Portugal, celebrado no Rio de Janeiro, em 16 de novembro de 1953, os países se comprometiam a apoiar-se mutuamente em questões diplomáticas que "ferissem seus interesses" (RAMPINELLI, 2007, pp. 83-85). Dessa forma, quando a Índia mobilizou seus negociadores internacionais para obter apoio no caso das colônias portuguesas, o Brasil foi um empedernido defensor dos interesses portugueses, argumentando que Goa, Damão e Diu não eram colônias, mas sim parte do império português (Províncias Ultramarinas) e que por isso deveriam se manter sob a gestão lusitana. A ocupação militar dos antigos entrepostos portugueses pela Índia foi denunciada pelos representantes brasileiros como um "ato imperialista" dos indianos. Ainda na esteira das contendas diplomáticas, a representação do Brasil, insatisfeita com os resultados das divergências políticas, partiu para a retaliação e proibiu, em 1962, a importação 
104 | InterAção

de material genético e de animais indianos para melhoria do rebanho zebuíno de criadores brasileiros, que era mestiço ${ }^{3}$. O governo indiano, respondendo, por sua vez, proibiu aos seus cidadãos que exportassem embriões e animais dessa raça para o Brasil (VIEIRA, 2007, p. 53-54).

As disputas diplomáticas e a "contenda dos zebus" ${ }^{4}$ marcaram por algum tempo as relações entre Brasil e Índia de modo negativo, porque os representantes diplomáticos da Índia passaram a considerar o Brasil como "submisso" aos interesses das antigas colônias e, posteriormente, das grandes potências, incapaz de se insurgir contra sua metrópole e ainda, mesmo depois de independente, advogar em favor dos antigos opressores europeus. $\mathrm{O}$ afastamento diplomático persistiu até a década de 1990, com exceção de algumas frustradas tentativas de retomar as relações entre os países 5 .

30 material genético do rebanho zebuíno indiano é valorizado pelos criadores brasileiros porque os animais são originários daquele país e ainda porque são preservados naturalmente, pois os indianos os utilizam apenas para a produção de leite e tração, em virtude de ser considerado um animal sagrado. Informações constantes na página eletrônica <http://www.zebuonline.com.br/pt/index.php>, visitado em 25 de fevereiro de 2011.

4 Este termo não é usual na bibliografia, mas espelha este restrito incidente internacional envolvendo Brasil e Índia. Cabe lembrar que a questão não foi levada adiante perante qualquer instituição jurídica internacional, ficando restrita apenas às determinações internas de cada país. Contudo, mesmo com a proibição expressa aplicada pelos governos nacionais, produtores brasileiros e indianos continuaram a realizar negócios nesse campo, mas sem 0 amparo legal. 0 tráfico de material genético só teve fim com sua regulamentação intergovernamental na década de 1990.

5 Com vistas a restabelecer a aproximação ocorreu com a visita da governante indiana Indira Gandhi, em 1968, no qual foram assinados acordos de cooperação que não saíram do papel. Na década de 1980 ainda foram celebrados mais alguns atos diplomáticos que acenaram para a possibilidade de estabelecimento de parcerias, mas esses acordos não eram mais do que intenções e, na prática, pouco significaram. (VIEIRA, 2007, p. 54) 
InterAção | 105

O singelo aumento das atitudes diplomáticas ao longo das últimas duas décadas pode ser mostrado por meio de dois recursos. Primeiro, mediante a análise da quantidade de "Atos Bilaterais Multitemáticos entre Brasil e Índia”, representados na Tabela 1, elaborada a partir de dados retirados da página eletrônica do Ministério das Relações Exteriores do Brasil. Segundo, pela observação das visitas governamentais realizadas por representantes brasileiros e indianos, no decorrer da década de 1990 até o ano de 2009. Os atos bilaterais firmados desde 1969 não significam, necessariamente, a execução das finalidades expressas em seus textos. Em outras palavras, Brasil e Índia demonstraram boa intenção diplomática ao assinarem os diversos acordos, mas a execução das determinações constantes nos textos dependeria, em última instância, do esforço de setores governamentais e privados em mobilizar recursos para tal finalidade.

\section{Tabela 1 - Atos Bilaterais* Multitemáticos Brasil - Índia (em vigor)}

\begin{tabular}{|c|c|}
\hline Ano & No de Atos** \\
\hline 1969 & 1 \\
\hline 1970 & 1 \\
\hline 1990 & 1 \\
\hline 1992 & 3 \\
\hline 1996 & 3 \\
\hline 1997 & 1 \\
\hline 1998 & 2 \\
\hline
\end{tabular}

\begin{tabular}{|c|c|}
\hline Ano & No de Atos** \\
\hline 2002 & 1 \\
\hline 2004 & 1 \\
\hline 2006 & 5 \\
\hline 2008 & 6 \\
\hline 2009 & 0 \\
\hline 2010 & 0 \\
\hline Total & 25 \\
\hline
\end{tabular}

Fonte: dados do Ministério das Relações Exteriores (elaboração própria) * a definição de atos bilaterais, de acordo com o MRE, compreende Acordos, Declarações, Convenções, Memorandos, Agendas e Programas.

** Dentre o número total de tipos de Atos celebrados há documentos intitulados Ajustes Complementares, que incrementam os atos anteriormente em vigor. 
106 | InterAção

Sobre estes Atos, algumas considerações são necessárias quanto a sua importância e conteúdo. Primeiro, o número de acordos celebrados entre Brasil e Índia, se cotejados a outros tradicionais parceiros brasileiros, como Argentina e Estados Unidos, é numericamente muito menor. Em comparação com o número de atos bilaterais assinados com a Argentina, por exemplo, há uma desvantagem extrema: Brasil e Argentina assinaram mais de duzentos atos bilaterais no mesmo período apontado na tabela ${ }^{6}$. Portanto, em termos absolutos, as relações bilaterais com o governo indiano correspondem a cerca de dez por cento das relações com um parceiro brasileiro tradicional como a Argentina ${ }^{7}$.

A segunda consideração diz respeito aos acordos nas áreas de cooperação científica e tecnológica e os de cunho comercial. Basicamente, estes são os atos que maior efetividade têm alcançado, principalmente por meio da exportação de etanol e da transferência de tecnologia para sua produção (acordos de 2006). Sobre os tratados comerciais, especificamente, ressalta-se a compra de aviões da Embraer para integrar a forças aéreas indianas, que tiveram de diversificar suas fontes de abastecimento em função da desintegração da União Soviética, seu tradicional fornecedor de produtos bélicos.

6 Para estabelecer essa proporção com maior precisão, considera-se apenas os atos bilaterais Brasil e Argentina a partir do ano de 1968 (visto que nenhum deles entrou em vigor em 1969, ano do primeiro acordo Brasil-Índia). Os primeiros acordos Brasil/ Argentina datam da primeira metade do século XIX.

7 Obviamente, não se analisa o teor dos mais de duzentos acordos bilaterais com a Argentina. A comparação aqui proposta é evidenciada em termos absolutos e serve apenas para demonstrar a diferença entre parceiros internacionais na história das relações exteriores do Brasil. 
InterAção | 107

A terceira ponderação é relativa aos acordos para utilização pacífica de energia nuclear. Apesar dos recorrentes acordos nesta área polêmica, há certa precaução por parte do Brasil em implementá-los devido às distintas concepções que ambos os países têm a respeito do tema. A Índia desenvolveu armas nucleares e ocasionalmente realiza testes, para demonstrar seu poderio para o rival regional, o Paquistão. Os últimos "testes", demonstrações explícitas de força, dataram de 1998 e foram alvo de críticas da diplomacia brasileira. O Brasil considera o desenvolvimento desta tecnologia exclusivamente para usos pacíficos (ALTEMANI DE OLIVEIRA, 2006, p. 7-8).

Outra inferência, relacionada ao aumento do interesse mútuo das diplomacias brasileira e indiana, indica um significativo crescimento nas relações políticas diplomáticas entre os dois países, a partir do ano 2000. Esse crescimento pode ser atribuído justamente aos renovados interesses dos representantes políticos em incrementar as relações entre os países, mas não significa o estabelecimento de primazia entre eles. O aumento do número de atos bilaterais nos anos de 2006 e 2008, correspondendo praticamente à metade do total apresentado na $\mathbf{T a}-$ bela 1, bem como o aumento das visitas diplomáticas (BALADÃO, 2009) são decorrência, principalmente, da aproximação oportunizada pelo Fórum de Diálogo IBAS e pelas reuniões dentro do Grupo BRIC e simbolizam a convergência conjuntural da política externa dos dois países. Não representam, contudo, uma reversão de tendências na política exterior brasileira e indiana, se comparado aos acordos com parceiros tradicionais. $\mathrm{O}$ grau de interdependência política entre estes países, embora crescente, continua pouco significante, visto que as parcerias internacionais entabuladas são resultado de aproximação recente e es- 
108 I InterAção

tão restritas à determinados campos de atuação.

Um último indício da divergência entre as políticas externas do Brasil e da Índia pode ser encontrado no trabalho elaborado pelo Centro de Estudos das Negociações Internacionais (CAENI), vinculado ao Departamento de Ciência Política da Universidade de São Paulo, e coordenado pelo Prof. Dr. Amâncio Jorge de Oliveira, relacionado às posições dos integrantes do IBAS sobre temas vinculados ao Comércio, Segurança, Meio Ambiente, Direitos Humanos e outros, discutidos nas organizações internacionais (OLIVEIRA, et al, 2006). Segundo este estudo se conclui que Índia e Brasil tiveram, ao longo do período recortado, um grau relativamente baixo de interesses comuns.

O objetivo de analisar o fórum IBAS pelo CAENI surgiu da indagação sobre qual o grau de interesse dos países integrantes em promover uma coalizão ou cooperação entre nações "com baixo grau de interdependência socioeconômica" (OLIVEIRA, et al, 2006, p. 490). Segundo os próprios autores, baseados em teorias elaboradas para interpretar processos de integração e formação de coalizões, o IBAS não busca se configurar uma área onde figure uma "interdependência endógena”, como nos processos de integração regional. Desejam sim, estabelecer parcerias "para lidar com problemas comuns, ou, ainda, de uma disposição governamental para induzir a ampliação da interdependência como forma de diversificação de parcerias, para além dos vínculos com grandes potências." (OLIVEIRA, et al, Idem.)

De acordo com o "índice de correlação bivariado" aplicado

8 Sobre o Índice de Correlação Bivariado, explicam os autores: "Foram criados indicadores que captam as preferências dos três países reveladas na OMC e na ONU. Cada 
InterAção | 109

para o conjunto de todos os temas, fica claro o diminuto grau de convergência internacional. Os diversos apontamentos estatísticos formulados pelo CAENI indicam que o Fórum permanente trilateral do IBAS é uma coalizão internacional permeada exclusivamente por interesses conjunturais comuns, geralmente, determinados pelos respectivos governos nacionais; e bastante frágil, quando consideradas as convergências bilaterais entre seus integrantes. Embora esteja claro que formas de cooperação Sul-Sul tenham a tendência a aumentar no decorrer dos anos, deve ter em conta que alguns dos principais países têm significativas divergências e objetivos distintos.

\section{Relações Comerciais bilaterais Brasil-Índia}

Em relação às trocas comerciais em períodos recentes pode-se concluir que, nos últimos anos, houve uma intensificação dos negócios entre Brasil e Índia. A Tabela 2 indica os números das transações nos últimos quinze anos, comparando as exportações entre os dois países. $\mathrm{O}$ que se nota é o vertiginoso crescimento das trocas comerciais, principalmente a partir do período de 2005/2006. Não por coincidência

voto na ONU e cada posição na OMC foram classificados segundo quatro categorias: voto a favor da resolução; voto contrário; abstenção; e ausência de prerrogativa de voto (para o caso de algum país não poder expressar suas posições nesses fóruns em algum período da amostra). Foram recolhidos dados para um período de onze anos (de 1994 a 2004). Foi utilizado o índice de correlação bivariado (entre dois países) para medir 0 grau de convergência ou divergência das preferências reveladas. Em uma escala de 0 a 1, quanto mais próximo de 1 for o resultado, maior a convergência de posicionamento do país em relação ao tema pesquisado. Quanto mais próximo de 0 , maior a divergência de posicionamento do país em relação ao tema." (OLIVEIRA, et al, 2006, p. 490-491) 
110 | InterAção

o incremento das transações comerciais bilaterais ocorre na sequência da instituição do Fórum Trilateral do IBAS, e também em função de outros mecanismos facilitadores, como a assinatura do acordo de comércio preferencial entre o Mercosul e a Índia, em 2004.

Tabela 2 - Exportações e Importações Brasil $\rightarrow$ Índia - 1996 a 2010

\begin{tabular}{|c|c|c|c|c|}
\multicolumn{2}{|c|}{ Exportaçoses Brasil $\rightarrow$ Índia } & \multicolumn{2}{c|}{ Importações Índia $\rightarrow$ Brasil } & Saldo \\
\hline Ano & $\begin{array}{c}\text { Valor } \\
\text { (em US\$-FOB) }\end{array}$ & Ano & $\begin{array}{c}\text { Valor } \\
\text { (em US\$-FOB) }\end{array}$ & -854.878 \\
\hline 1996 & 184.915 .784 & 1996 & 185.770 .662 & -49.857 .790 \\
\hline 1997 & 166.296 .026 & 1997 & 216.153 .816 & -66.783 .146 \\
\hline 1998 & 144.886 .031 & 1998 & 211.669 .177 & 143.864 .596 \\
\hline 1999 & 313.906 .319 & 1999 & 170.041 .723 & -53.904 .588 \\
\hline 2000 & 217.450 .483 & 2000 & 271.355 .071 & -257.383 .384 \\
\hline 2001 & 285.407 .449 & 2001 & 542.790 .833 & 80.553 .436 \\
\hline 2002 & 653.737 .166 & 2002 & 573.183 .730 & 67.952 .203 \\
\hline 2003 & 553.696 .147 & 2003 & 485.743 .944 & 96.483 .416 \\
\hline 2004 & 652.553 .131 & 2004 & 556.069 .715 & -64.984 .001 \\
\hline 2005 & 1.137 .930 .199 & 2005 & 1.202 .914 .200 & -535.062 .311 \\
\hline 2006 & 938.889 .310 & 2006 & 1.473 .951 .621 & -1.211 .419 .757 \\
\hline 2007 & 957.854 .449 & 2007 & 2.169 .274 .206 & -2.461 .962 .116 \\
\hline 2008 & 1.102 .342 .120 & 2008 & 3.564 .304 .236 & 1.223 .943 .731 \\
\hline 2009 & 3.415 .040 .261 & 2009 & 2.191 .096 .530 & -750.036 .249 \\
\hline 2010 & 3.492 .350 .604 & 2010 & 4.242 .386 .853 & \\
\hline
\end{tabular}

Fonte: ALICEWEB/MDIC - Balança Comercial Elaboração própria.

Embora significativo o aumento das transações, deve-se compará-lo com os valores individuais de exportação de Brasil e Índia. Os dados das exportações brasileiras destinadas à Índia estão contrastados 
em relação, primeiro, ao volume remetido ao continente asiático (exclusive Oriente Médio), segundo, ao volume total, o que permite representar a relevância do mercado indiano para o Brasil no contexto da Ásia e do mundo; e terceiro, em comparação com alguns dos principais parceiros comerciais brasileiros. A tabela 3 indica esses números.

Tabela 3 - Exportações Brasil $\rightarrow$ Índia em perspectiva comparada (20042010) (em US\$)

\begin{tabular}{|r|c|c|c|c|c|} 
Ano & $\begin{array}{c}\text { Exportação } \\
\text { Brasil-Índia }\end{array}$ & $\begin{array}{c}\text { Exportação Brasil- } \\
\text { Ásia }\end{array}$ & $\begin{array}{c}\text { \% em } \\
\text { relação ao } \\
\text { comércio } \\
\text { Brasil- } \\
\text { Asia }\end{array}$ & $\begin{array}{c}\text { Exportação Brasil- } \\
\text { Mundo }\end{array}$ & $\begin{array}{c}\text { \% em } \\
\text { relação ao } \\
\text { total de } \\
\text { exportações } \\
\text { do Brasil }\end{array}$ \\
\hline 2004 & 652.553 .131 & 14.577 .190 .712 & 4,5 & 96.677 .838 .776 & 0,7 \\
\hline 2005 & 1.137 .930 .199 & 18.565 .977 .366 & 6,1 & 118.529 .184 .899 & 1,0 \\
\hline 2006 & 938.889 .310 & 20.816 .366 .719 & 4,5 & 137.807 .469 .531 & 0,7 \\
\hline 2007 & 957.854 .449 & 25.086 .433 .209 & 3,8 & 160.649 .072 .830 & 0,6 \\
\hline 2008 & 1.102 .342 .120 & 37.570 .970 .683 & 2,9 & 197.942 .442 .909 & 0,6 \\
\hline 2009 & 3.415 .040 .261 & 40.239 .044 .462 & 8,5 & 152.994 .742 .805 & 2,2 \\
\hline 2010 & 3.492 .350 .604 & 56.272 .595 .819 & 6,2 & 201.915 .285 .335 & 1,7 \\
\hline Principais parceiros comerciais do Brasil em 2010 (China, EUA, Argentina) \\
\hline Brasil-China (2010)
\end{tabular}

Fonte: ALICEWEB/MDIC - Balança Comercial Elaboração própria.

O que se conclui é que as negociações com a Índia, no período indicado, é que, embora o volume de valores negociados esteja em vertiginoso crescimento, ele não se torna tão distinto se comparado ao total negociado com a Ásia e com todo o volume de transações bra- 
112 | InterAção

sileiras. Pelo que se constata, apenas em três ocasiões o valor transacionado passa dos seis por cento em relação à Ásia e apenas em 2009 atinge cifra maior que dois por cento do total das exportações brasileiras. Se compararmos as exportações do Brasil com a Índia com as de Brasil e China, no ano de 2010, vemos que é três vezes menor. Além disso, como indicado no ano de 2008, onde se iniciou a crise econômica internacional mais recente (mais conhecida por "crise imobiliária dos EUA"), observa-se a fragilidade na parceria comercial Brasil-Índia, denotada pelo decréscimo em relação à tendência anterior, pelo menos no que se refere ao comércio brasileiro com a Ásia.

No sentido inverso do fluxo de exportações, ou seja, as originárias na Índia com destino ao Brasil (em comparação ao total de exportações indianas) se constata idêntica tendência e avaliação ao se observar as informações retiradas da página eletrônica do Departamento de Comércio do Governo Indiano. Para os períodos de 2006 a 2010, as exportações indianas para o Brasil representam apenas entre 1 e 1,5\% em relação ao total exportado, conforme Tabela 4, a seguir.

Tabela 4 - Quadro de Exportações Índia $\rightarrow$ Brasil - 2006 - 2010 (em US\$)

\begin{tabular}{|c|c|c|c|c|}
\hline Anos & $2006-2007$ & $2007-2008$ & $2008-2009$ & $2009-2010$ \\
\hline Valor - Exp. para o Brasil & $1.449 .250,00$ & $2.525 .900,00$ & $2.651 .430,00$ & $2.414 .290,00$ \\
\hline Valor - Exp. Totais & $26.414 .050,00$ & $163.132 .180,00$ & $185.295 .360,00$ & $178.745 .460,00$ \\
\hline $\begin{array}{c}\text { \% em relação ao total das } \\
\text { exportaçõs indianas }\end{array}$ & 1.14 & 1.54 & 1.43 & 1.35 \\
\hline
\end{tabular}

Fonte: Governo Indiano - Department of Commerce, Export Import Data Bank

Uma possível interdependência política e econômica entre Brasil e Índia, pelo menos em se tratando da sua história diplomática e das 
relações comerciais estabelecidas, não pode ser constatada. Apenas nos fóruns internacionais trilaterais e multilaterais as parcerias ${ }^{9}$ se mostraram mais significativas. Na seção subsequente é indicado e examinado o papel de liderança e parceria entre os dois países em fóruns multilaterais de comércio, financiamento e segurança, como o G-20 e o G-4, entre outros, e na instituição e consolidação de espaços políticos internacionais como o IBAS e o BRIC.

\section{Brasil e Índia nos fóruns multilaterais}

O destaque entre as relações Brasil e Índia está nas diversificadas formas de cooperação que esses países empreenderam no campo multilateral. A participação e, notadamente, a liderança desses dois grandes Estados periféricos é constatada com certa regularidade nos organismos internacionais, políticos e econômicos, e suas rodadas de negociações.

A atuação articulada entre representantes governamentais brasileiros e indianos foi importante na criação da Conferência das Nações Unidas sobre Comércio e Desenvolvimento (UNCTAD), na década de 1960. Também neste período, e como decorrência da mobilização dos países mais pobres ou, os naquela época integrantes do Terceiro Mundo, foi organizado o G-77, incluindo os países subdesenvolvidos e em desenvolvimento. Teve especial destaque na criação deste amplo conjunto

9 Utilizam-se os termos "parceria" e "cooperação" quando se referem aos fóruns multilaterais porque se trata exclusivamente de associações objetivas, em temáticas internacionais, onde a unidade de posições se dá para atingir objetivos comuns. Essas parcerias não têm comprometimento internalizado e formalizado como 0 Mercado Comum do Sul (MERCOSUL), por exemplo. 
114 | InterAção

de países a formação, por parte de potências médias, da ideia de não alinhamento na luta entre os blocos capitalistas e socialistas. A Índia participou ativamente na criação do Movimento dos Não Alinhados (MNA), o Brasil nunca o compôs formalmente, mas assistiu a algumas das suas reuniões como observador.

Ainda dentro da experiência e espírito da criação da UNCTAD e da organização do G-77, Brasil e Índia fundaram, com outros membros, o G-24, em 1971. Este grupo, ainda ativo, visa formular proposições aos organismos financeiros internacionais, como o Banco Mundial (BIRD/AID) e o Fundo Monetário Internacional (FMI). A necessidade da sua criação deriva da reação ao predomínio dos países que futuramente integrariam o G-7 $7^{10}$ na definição de políticas de financiamento internacional. Considerava-se, à época, que tanto BIRD/AID, quanto FMI, não atendiam aos interesses dos países menos desenvolvidos e eram na verdade, organismos dedicados a manter a radical desigualdade econômica entre as nações, concedendo privilégios em forma de empréstimos apenas àqueles que se "comportassem" de acordo com suas determinações. Esta tendência ficaria mais patente nas décadas de 1980 e 1990 quando FMI e BIRD impõem aos países pobres planos de reformas econômicas e sociais em troca de financiamento.

Outro grupo importante (e mais recente) criado em decorrência da liderança de Brasil e Índia, e também da China, foi o G-20, atuante nas rodadas de negociação da OMC destinadas à regular o sistema de

100 G-7 foi criado em 1975 e incluía as maiores potências econômicas do mundo à época: EUA, Japão, Alemanha, Reino Unido, França, Itália e 0 Canadá. Desde 1998 passou a ser 0 G-8 com a inclusão da Rússia. 
comércio e investimentos internacionais. Este articulado grupo é liderado por países considerados "em desenvolvimento", como China, África do Sul, Argentina, Brasil e Índia. Sua atuação na OMC deu sinais de vida na Rodada de Doha, em 2001, quando os países em desenvolvimento se organizaram para resistir às pressões dos países ricos para definir e aprovar pautas econômicas pouco interessantes. Contudo, foi somente na reunião interministerial de Cancún, em 2003, que o G-20 formalizou a coalizão diante da negligência dos países desenvolvidos em tratar das referidas questões agrícolas e priorizar temas relacionados ao comércio e economia, os chamados "Temas de Cingapura".

O G-4 é outra associação mundial na qual Brasil e Índia tiveram responsabilidade na formação. Além desses dois países conta também com a Alemanha e o Japão. Seu escopo é alterar a configuração do Conselho de Segurança da ONU, propiciando a elevação dos seus quatro membros (além de um país africano) à categoria de "permanentes" do CS. Portanto, se a proposta for aprovada, o CS passará a ter 10 países com direito ao poder de veto, ao contrário dos atuais cinco (EUA, Rússia, China, Reino Unido e França). A intenção brasileira e indiana de integrar permanentemente o CS é sustentada por ambos devido ao papel chave que estes países desempenham na suas respectivas regiões. Do lado indiano, seu poder nuclear, combinado ao tamanho de sua população e ao "combate aos grupos terroristas" são argumentos levantados para justificar seu ingresso como membro permanente.Já o Brasil indica sua reiterada participação brasileira em forças de paz da ONU e sua liderança na criação da "Zona de Paz" (CERVO, 2008), na América do Sul como fatores definitivos de sua entrada no CS. Outro fator que contribui à candidatura brasileira é o fato de ter sido eleito em nove ocasi- 
116 | InterAção

ões na qualidade de membro provisório, detendo o recorde de presenças como integrante sem direito ao veto.

O Fórum permanente de discussões Índia, Brasil e África do Sul - IBAS foi oficialmente formado em 2003, como resultado da "Declaração de Brasília”. Desde sua criação alcançou objetivos significativos, como a criação de um Fundo Internacional de Combate à Fome e à Pobreza, ações de cooperação em Ciência e Tecnologia e propôs a polêmica instituição de uma Área de Livre Comércio que envolveria a Índia, o Mercosul e a SACU (integrado por África do Sul e parceiros regionais $)^{11}$. Além das ações e propostas, o Fórum IBAS pretende abarcar em seu conjunto uma multiplicidade de temas de interesse mundial, como meio ambiente e direitos humanos. Com maior ênfase, está a questão da segurança internacional e subtemas derivados dela ${ }^{12}$, como terrorismo, imigração, tráfico de drogas, criminalidade, fome, epidemias e outros (DADA; KORNEGAY, 2007).

A história da aproximação dos países-membros do IBAS, contudo, está localizada no ano de 1997, quando se iniciou uma batalha

11 A Área de Livre Comércio Trilateral Índia-Mercosul-SACU foi proposta em outubro de 2007, resultado de cúpula do IBAS. A área incluiria, além da Índia, os países mercosulinos (Argentina, Brasil, Paraguai e Uruguai) e os da SACU - Southern Africa Customs Union (Botsuana, Lesoto, Namíbia, África do Sul e Suazilândia).

12 Convém considerar que o IBAS amplia 0 conceito de segurança internacional inserindo em seu cerne matérias como a fome e as epidemias (de AIDS, por exemplo). Ademais, a iniciativa de tratar de tema tão sensível, e ainda redimensioná-lo, decorre da intenção implícita de se contrapor ao conceito de segurança internacional defendido pela política externa estadunidense, pautada quase que exclusivamente no combate ao terrorismo. Também, a iniciativa de alargar a agenda de segurança mundial, incluindo a fome como causa da insegurança, denota a intenção tornar mais evidente as diferenças sociais entre o Norte rico e um Sul pobre. 
comercial e diplomática envolvendo África do Sul, Índia e Brasil contra, principalmente, os Estados Unidos, e também alguns países da União Européia, em torno do contencioso das patentes farmacêuticas, na qual as nações em desenvolvimento, articulados em torno de um propósito comum, a quebra da patente para o coquetel de remédios anti-HIV, obtiveram uma vitória ante os EUA que, por pressão da opinião pública interna e internacional, recuaram em suas exigências na OMC (OLIVEIRA, 2005).

O grupo BRIC ou Aliança dos Países Baleia, a associação mais recente envolvendo Brasil e Índia, tem uma potencial importância política, pois reúne quatro grandes economias emergentes. Desde sua fundação formal em 2008, ainda não se implementou significativas medidas práticas, muito embora em seus discursos e comunicados, resultantes das três cúpulas realizadas em maio de 2008, junho de 2009 e abril de 2010, demonstrem crescentes interesses comuns sobre temas importantes ligados ao sistema financeiro mundial, às questões de segurança, ao aquecimento global e postulem uma atuação coordenada em organizações mundiais como o FMI, Banco Mundial, OMC. Resta evidente a importância do diálogo entre os membros do grupo como forma de contestar a hegemonia americana, tanto no que se refere à definição da agenda internacional de negociações, quanto às decisões a serem tomadas.

\section{Análise do atual contexto internacional e a ascensão das formas de co- operação Sul-Sul}

A cooperação Sul-Sul não pode ser classificada como um fenômeno recente nas relações internacionais. Mesmo durante o perío- 
118 | InterAção

do da Guerra Fria havia a percepção de que as clivagens entre capitalismo e socialismo, orquestradas pelos líderes dos blocos controversos, atendiam a interesses específicos e não promoveriam, ao contrário do que se esperava, o crescimento econômico dos países periféricos e também não reduziriam as desigualdades entre os países localizados no hemisfério Norte e os desprovidos do Sul. O Movimento dos Não Alinhados, o G77 e outras manifestações terceiro-mundistas isoladas, atestam que a cooperação Sul-Sul já se ensaiava nas décadas de pleno conflito (indireto) entre os Estados Unidos e União Soviética.

Com o fim da Guerra Fria poderia se esperar uma eclosão espetacular dessas articulações Sul-Sul em contraposição ao Norte, pois a luta ideológica não ocuparia mais a agenda internacional e as diferenças socioeconômicas se tornariam mais evidentes. Esse despertar dos "menos abastados", contudo, não ocorreu por três motivos interligados.

O primeiro deles foi o obscurantismo geral em que caíram as nações menos desenvolvidas, plenamente contentadas com as maravithas que a abertura dos mercados poderia vir a promover, sem a menor prova de que esse prometido aumento da riqueza geral pudesse, de fato, se concretizar. O segundo motivo foi a vinculação que os países sub e em desenvolvimento mantinham com as grandes potências capitalistas, obrigando-os a preservar certos laços e comportamentos condizentes com a suposta "nova ordem". E, o último motivo remete à diversidade de projetos e propostas políticas e econômicas, muitas vezes contraditórias, que os países pobres apresentavam, inviabilizando certas alianças e coalizões.

Contudo, a reversão dessa conjuntura e a possibilidade de aproximação entre, pelo menos, um reduzido grupo de países $\mathrm{em}$ desenvolvimento se deu no fracasso dos projetos neoliberais imple- 
mentados ao longo da década de 1990 e na reorientação da política internacional americana operada desde fins de 2001, visando o restabelecimento da hegemonia política e econômica (enfraquecida) no cenário internacional ${ }^{13}$.

Ficou evidente para Brasil e Índia, ao primeiro pela experiência, e ao segundo pela observação, que a cooperação em torno de interesses comuns é condição indispensável para buscar uma colocação mais proveitosa no sistema internacional. Não se trata, pelo averiguado, de projetar um mundo novo, de promover mudanças de ordem sistêmica, mas sim de alterar a "clássica" divisão entre periferia, semi-periferia e centro, proporcionando uma redistribuição internacional de poder, no cenário transformado pela globalização. Contudo, para que essa necessária parceria seja mais bem estruturada é mister comparar os dois países para averiguar quais são os fatores positivos e negativos para sua aproximação.

$\mathrm{Na}$ tentativa de oferecer um resumo sobre este ponto e esquematizá-lo, e com base nas interpretações das leituras consultadas para este texto, foi elaborado o Esquema 1, que indica os fatores positivos e negativos nas relações entre Brasil e Índia. Trata-se de um esquema simples que aponta apenas quais as características de cada país que podem aproximá-los ou afastá-los. Ressalve-se, contudo, que esses aspectos têm pesos diferentes no condicionamento das relações

13 A reversão da política exterior estadunidense aqui situada em 2001 faz referência à tentativa, desde então, de localizar no cenário internacional um novo "inimigo total" contra o qual possa mobilizar apoiadores (R0J0, 2008). Trata-se da eleição do terrorismo, em lugar do comunismo de outrora, como fator agregador das lutas do Ocidente, proporcionando a reconstrução da hegemonia política internacional centrada na América do Norte. 
120 I InterAção

exteriores. A opção pelo formato de "esquema" se destina à melhor visualização e maior objetividade.

\section{Esquema 1 - Fatores potencialmente positivos e negativos nas relações Brasil e Índia}

\begin{tabular}{|l|l|}
\multicolumn{1}{|c|}{ Fatores Positivos } & \multicolumn{1}{c|}{ Fatores Negativos } \\
\hline • Interesses Comuns, de acordo com & • Formação histórica dos países. \\
a Teoria da Inserção Internacional de & • Diferenças culturais. \\
Grandes Países Periféricos ou Potências & • Distância geográfica. \\
Intermediárias (GUIMARÃES, 1998). & • Passado de algumas divergências \\
- Grandes populações e territórios. & diplomáticas e políticas. \\
- Histórica Cooperação Multilateral. & • Projetos de desenvolvimento nacional \\
• Forte característica industrial, com a & diferentes. \\
intervenção estatal (indústrias de base). & • Não possuem uma grande comunidade \\
- Ausência de graves rivalidades históricas. & de "diáspora" do outro. \\
- Tendência conjuntural de cooperação & • Modelos de Desenvolvimento \\
Sul-Sul. & Introjetados. \\
\hline
\end{tabular}

Fonte: Elaboração própria.

\section{CONSIDERAÇÕES FINAIS}

As relações bilaterais entre Brasil e Índia tiveram um incremento apenas em anos recentes. Contribuiu definitivamente para esta realidade a aproximação consubstanciada historicamente nos fóruns multilaterais e trilaterais e, também, a tendência de cooperação entre os países líderes do hemisfério Sul, em favor de interesses comuns em certas conjunturas. Contudo, suas dificuldades de convergência política em campos diversos, como mostrado pelo estudo do CAENI, associadas ao baixo grau de interdependência, fazem com que essa articulação bilateral seja lenta e controlada. 
InterAção | 121

Por outro lado, ao analisar as relações multilaterais o que se observa é a atuação de diplomacias conscientes das condições de seus países no cenário internacional. A atuação coordenada dos dois corpos diplomáticos foi decisiva para estruturar os diferentes Grupos) com objetivos múltiplos. A atuação do G20 principalmente produziu o entendimento por parte dos países desenvolvidos que o ambiente internacional da era da globalização já não mais partia de vinculações automáticas; os fez perceber que o "jogo de xadrez" da Guerra Fria perdera sua validade enquanto mecanismo de mobilização mundial. E, mais importante, a liderança organizada em Grupos de atuação em espaços multilaterais fez de Brasil e Índia atores conscientes do poder de barganha da maioria, em circunstâncias onde a democracia era praticada apenas no plano discursivo.

O que esperar dessa cooperação, tendo em vista os seus avanços e considerando as dificuldades conceituais para se classificar o sistema internacional (uni, multi, ou unimultipolar)? Pode-se especular que as alianças entre esses dois gigantes têm grande chance de serem marcadas pelo sucesso. Os recentes acordos políticos internacionais do IBAS e do BRIC reforçam essa tendência. Contudo, é inegável o peso do fator conjuntural na constituição de tais grupos e a ausência de laços históricos mais fortes entre os países-membros, o que poderia garantir sua integridade e maior capacidade de sobrevivência.

\section{REFERÊNCIAS BIBLIOGRÁFICAS}

CERVO, Amado Luiz. Inserção internacional: formação dos

conceitos brasileiros. São Paulo: Saraiva, 2008. 
122 | InterAção

GOVERNO INDIANO - DEPARTMENT OF COMMERCE. Export Import Data Bank. Disponível em: <http://commerce.nic.in/ eidb/ecntq.asp>, acesso em 25 de março de 2011.

GUIMARAES, Samuel Pinheiro. Desafios e dilemas dos grandes países periféricos: Brasil e Índia. Revista Brasileira de Política Internacional - RBPI, 1998, v. 41, n. 1, pp. 108-131.

JERVIS, Robert. Realism, neoliberalism, and cooperation: understanding the debate. International Security, v. 24 n.1, Verão/1999, pp. 42-63.

KEOHANE, Robert O. After Hegemony: Cooperation and Discord in the World Political Economy. Princeton, NJ: Princeton University Press, 1984.

LIMA, Maria Regina Soares de. A política externa brasileira e os desafios da cooperação Sul-Sul. Revista Brasileira de Política Internacional - RBPI, 2005, v. 48, n. 1, pp. 24-59.

McLEOD, John. History of India. Westport: Greenwood Publishing Group, 2002.

MILNER, Helen. International Theories of Cooperation among Nations: A Review Essay. World Politics, v. 44, n. 3, Abril/1992

MINISTÉRIO DAS RELAÇÕES EXTERIORES - MRE. Atos Bilaterais - Índia. Disponível em: <http://www2.mre.gov.br/dai/biindia. htm>, Acesso em: 09/03/2011.

\section{MINISTÉRIO DAS RELAÇÕES EXTERIORES - MRE.}

Informações Gerais sobre o Grupo BRIC. Disponível em: <http:// www2.mre.gov.br/dibas/informacoes_gerais_Bric.pdf $>$, Acesso em: 10/03/2011. 
InterAção | 123

\section{MINISTÉRIO DO DESENVOLVIMENTO INDÚSTRIA} E COMÉRCIO EXTERIOR - MDIC. ALICEWEB. Balança Comercial. Disponível em: <http://aliceweb.desenvolvimento.gov.br/> Acesso em: 10/03/2011.

OLIVEIRA, Amâncio Jorge Nunes de; ONUKI, Janina; OLIVEIRA, Emmanuel de. Coalizões Sul-Sul e Multilateralismo: Índia, Brasil e África do Sul. Contexto Internacional, Rio de Janeiro, 2006, vol. 28, no 2, julho/dezembro, pp. 465-504.

OLIVEIRA, Henrique Altemani de. As Parcerias Brasil-China e Brasil-Índia: complementares ou excludentes? VI Jornadas Sobre Triangulación. 2006. Disponível em: <www.iberoasia.org/jornadas/ Altemani.pdf $>$, Acesso em: 07/03/2011.

OLIVEIRA, Marcelo Fernandes de. Alianças e coalizões internacionais do governo Lula: o Ibas e o G-20. Revista Brasileira de Política Internacional - RBPI, 2005, v. 48, n. 2, pp. 55-69.

ONU - Organização das Nações Unidas. Comisiones principales. Disponível em: <http://www.un.org/es/ga/maincommittees/index. shtml $>$, Acesso em: 20/03/2011.

PINTO, Paulo Antônio Pereira. China e Índia: emergência e impacto cultural. Revista Brasileira de Política Internacional - RBPI, 2007, v. 50, n. 1, pp.86-101.

RAMPINELLI, Waldir José. A política internacional de JK e suas relações perigosas com o colonialismo português. Lutas Sociais (PUCSP), 2007, v. 17/18, p. 83 -98.

ROJO, Raúl Enrique. Da velha Guerra Fria ao novo "Inimigo Total". 2004. Disponível em: <http://www.cedep.ifch.ufrgs.br/Textos_Elet/pdf/ Rojo.pdf>. Acesso em: 13/04/2011. 
124 | InterAção

VIEIRA, Maíra Baé Baladão. Relações Brasil-Índia (1991-2006).

Porto Alegre: Ed. da UFRGS, 2009.

VIZENTINI, Paulo Fagundes. Os dez anos que abalaram o século 20:

a política internacional de 1989 a 1999. Porto Alegre: Novo Século, 1999.

ZEBU ONLINE. Disponível em: <http://www.zebuonline.com.br/pt/ index.php> Acesso em: 12/04/2011. 